\title{
TXALAPARTA Y VANGUARDIA, RUIDO Y MÚSICA
}

\author{
Enrique Hurtado Mendieta \\ Universidad del País Vasco /Euskal Herriko Unibertsitatea \\ Dpto. Arte y Tecnología.
}

\section{Resumen}

La txalaparta es una tradición musical del País Vasco de gran riqueza y complejidad rítmica que es tocada por dos intérpretes en alternancia. La txalaparta está directamente relacionada con la experimentación musical de los años 60 , momento de su renacimiento, pero recientemente ha sufrido cambios rítmicos y tonales para acomodarse a la música europea clásica. Su recuperación es un fenómeno muy interesante ya que en la txalaparta tradicional hay características de interés para la música experimental pero, a la vez, su recuperación ocurre en un entorno cultural de vanguardia. Entre los aspectos formales y conceptuales comunes están la libertad de elegir dentro de unas reglas predefinidas y la interrelación entre los intérpretes a través de la improvisación, la exploración del timbre, el uso de la repetición y el pulso, o la falta de interés por la melodía.

Palabras clave: TXALAPARTA; VANGUARDIA; EXPERIMENTAL; IMPROVISACIÓN; MINIMAL

\section{TXALAPARTA AND AVANT-GARDE, NOISE AND MUSIC}

\section{Abstract}

The txalaparta is a musical tradition from the Basque Country of great richness and complexity, that is played by two interpreters in alternance. The txalaparta has a strong relationship to the musical experimentation in the 1960s, where it rediscovery happened, but recently it has undergone rhythmical and tonal changes to accommodate to classical european music. Its recovery is a very interesting process because in the traditional txalaparta there are characteristics which are of the interest of experimental music, but at the same time, its recovery happens within an avant garde cultural context. The common formal and conceptual characteristics encompass the freedom of choice framed by rules and the interrelation between players through improvisation, timbral exploration, the use of repetition and pulse, or the lack of interest for tonality.

Keywords: TXALAPARTA; AVANT GARDE; EXPERIMENTAL; IMPROVISATION; MINIMAL

Hurtado Mendieta, Enrike. 2015. "Txalaparta y vanguardia, un análisis de sus características comunes”. AusArt 3 (2): 58-68. D0I: 10.1387 /ausart.15934

\section{AUSART}


La txalaparta es una tradición musical percusiva originaria de las zonas rurales del País Vasco que es tocada por al menos dos intérpretes en alternancia, lo que genera un ritmo de gran riqueza y complejidad, habitualmente improvisado. El instrumento consiste en una o más tablas de madera dispuestas horizontalmente sobre soportes y que son percutidas verticalmente por palos de madera, llamados makilas. La txalaparta es improvisada mediante un juego de acción-respuesta entre los intérpretes que se reparten el compás en alternancia. Esta forma de toque es muy poco habitual y da lugar a una peculiar y compleja forma de interacción entre los intérpretes. A principios de los años 60 estaba prácticamente desaparecida cuando a mitad de la década, y dentro del movimiento de renovación de la cultura vasca, se produce su redescubrimiento y recuperación.

\section{CONTEXTO, INVESTIGACIONES PRECEDENTES}

La txalaparta ha sido poco estudiada por la investigación académica hasta hace pocos años. Existen solo algunos artículos en revistas académicas, generalmente descriptivos y principalmente centrados en aspectos sociológicos o antropológicos (Beltran 1988b; Suso 2004; Leaf 2007). En 2012, Escribano realiza la primera tesis doctoral centrada en la txalaparta en la que analiza la recuperación de la txalaparta en el contexto socio-político vasco. Anteriormente existía un trabajo de máster sobre la afinación de las tablas (Gambra 2008) pero solo un artículo que trataba en aspectos musicales (Sánchez y Beltran 1998), hasta que la realización de dos tesis recientemente (Euba 2015; Hurtado 2015). Los principales trabajos no académicos de divulgación sobre la txalaparta han sido realizados por los propios intérpretes (Goiri 1996). El autor más prolífico es Beltran, con dos monografías (2004, 2009a), numerosos artículos en revistas (1988a, 1988b, 2001a, 2001b, 2007) y dos documentales $(1985,2009 b)$.

\section{LA EXCEPCIONALIDAD}

La txalaparta ha sido descrita, como en el programa de los Encuentros de Pamplona, como "música primitiva vasca". También ha sido calificada como 
"instrumento primitivo" (Aramburu 1991, 194), "pastoril, nacido en los bosques, 'mítico'” (Bengoa en Euba 2006, 74), y ha sido calificada de "particular", como se desprende de las palabras del propio Beltran $(2004,118)$. De ella se ha dicho que "...musika baino gehiago, zentzu logikorik gabeko soinua egiten $d u$, abangoardiatik hurbil"' (Kortazar 1998, 303). Sus mismos intérpretes la han considerado como "no musical" por su naturaleza rítmica, como afirmaban Huts-Hitz (1979) en Euba (2006, 110), y en general como salvaje y alejada de la música académica. El músico Tomás San Miguel dice: "La txalaparta es como un caballo salvaje, con la pareja de txalapartaris en calidad de domadores. Yo soy un músico académico que se ha dejado asilvestrar por la llamada de la tribu" (Neira 2006).

Los motivos de esta excepcionalidad son variados. Por un lado hasta finales de los años 60 la txalaparta era algo desconocida incluso en los lugares donde se conservó la tradición, por otro, tenemos la represión que la cultura vasca sufrió durante el franquismo y el rechazo a la cultura rural por una parte de la población (Beltran 2009a, 85). Tampoco son ajenas a la falta de interés de músicos e investigadores algunas de sus principales características formales. Al ser principalmente improvisada no existe un repertorio que se pueda practicar y popularizar, además el carácter inestable que su ritmo ha tenido hasta hace bien poco, dificulta su integración rítmica en música "normal" (Zabala 2003, 81, 84; Escribano 2012,234 ) y esta no se ha producido de forma sistemática hasta los años 90, tras la introducción de cambios en el ritmo tradicional.

Entre estos cambios, destaca el del acento métrico, que actualmente ha pasado al primer golpe -como en música reglada- mientras que anteriormente iba en el último. Así mismo, a partir de los años 90 se modifica el ritmo espaciando los golpes para que sea más regular y homogéneo, y por lo tanto susceptible de ser usado con otros instrumentos. También se presta atención a conceptos de percusión como las subdivisiones y el pulso, y en algunos casos, pierde importancia la alternancia entre intérpretes. Finalmente, hay que destacar que es habitual encontrar músicos de txalaparta sin formación musical alguna, lo que añade un aura de "primitivismo" que probablemente ha alejado a muchos músicos con formación musical y seguramente ha llevado a que haya sido considerada como una tradición interesante desde el punto de vista etnográfico, pero no desde el musical.

En el ámbito tonal y melódico, Euba $(2004,32)$ apunta a un proceso que denomina xilofonización y que se produce con la introducción de tablas afinadas a finales de los años 90 . Este cambio transforma la naturaleza de la txalaparta 
acercándola al xilófono o la marimba y plantea varias paradojas, ya que la naturaleza inarmónica del sonido de la txalaparta dificulta su afinación, lo que crea una dicotomía al oscilar entre su tradicional naturaleza percusiva y una nueva naturaleza melódica/armónica (43).

En relación a la "normalización" rítmica y tonal que está experimentando la txalaparta, es interesante acudir a las reflexiones de Bailey, músico e investigador de la música improvisada, donde plantea que muchos estilos y músicas populares, al ser integradas en la tradición clásica europea pierden sus características originales, como la improvisación o la riqueza rítmica y tonal, al intentar acomodarse a las escalas y métricas de la música clásica (2010, $53,57,65)$.

Como vemos para muchos la txalaparta está más cerca del ruido que de la música, sin embargo, desde el punto de vista del arte y la música contemporáneos, la txalaparta está relacionada con la experimentación musical de los años 60 , momento en el que se produjo su renacimiento. Este es un fenómeno doblemente interesante; como en otras músicas populares, en la txalaparta tradicional hay características de interés para la música experimental, pero a la vez, su recuperación ocurre en un entorno cultural influenciado por la vanguardia a través del artista Jorge Oteiza. El cantautor vasco Benito Lertxundi califica la recuperación de la txalaparta de una auténtica reinvención debido al cambio de contexto y función que sufre (Escribano 2012, 120). Autores actuales, como Euba $(2006,158 ; 2012,156-8)$ y Escribano $(2012,56)$, articulan planteamientos similares, a la luz del análisis en torno al origen y propósito de las tradiciones realizado en Hobsbawm y Ranger (1983), sin duda muy interesante al analizar el proceso experimentado por la txalaparta durante su recuperación.

\section{LOS ENCUENTROS DE PAMPLONA}

Los Encuentros de Pamplona, en 1972, fueron organizados por el músico Luis de Pablo y el artista José Luis Alexanco y fueron originalmente pensados para tener continuidad en formato bienal. Allí se dieron cita hasta 350 artistas de todo tipo de disciplinas y orígenes. El martes 27 de junio de 1972, los hermanos Artze tocaron en el exterior del Museo de Bellas Artes de Pamplona sorprendiendo enormemente a los asistentes (Hontañon 1972, 81). Entre ellos estaban 
músicos como John Cage, Steve Reich, Walter Marchetti, Luis De Pablo, Mikel Laboa y probablemente David Tudor, entre otros. En una entrevista telefónica con Euba (25 de noviembre del 2009) Reich afirma que convenció a varios de los músicos que le acompañaban, para asistir a la actuación de txalaparta y que posteriormente hablaron con los hermanos Artze. Según Brunel (1972), los intérpretes de la composición Drumming (1970-1971) en los Encuentros fueron Michael Nyman, Gavin Bryars, Cornelius Cardew y Alvin Curran (Cuyás 2010, 360). Bryars afirma (comunicación personal, 30 octubre de 2014) que los músicos ingleses participantes (Cardew, Nyman y Bryars) llegaron a Pamplona dos días después del concierto de los Artze, con lo que es imposible que asistieran, pero que algunos músicos y bailarines estadounidenses que también acompañaban a Reich habían llegado días antes. Entre ellos estaban Art (Arthur) Murphy, Jim Preiss, Frank Clayton, Jay Clayton, Steve Chambers, Joan LaBarbara, Russ Hartenberger y Laura Dean.

Una de las novedades que presenta la actuación de los hermanos Artze en los Encuentros es que, por primera vez, la actuación constó únicamente de txalaparta. Hasta el momento, sus actuaciones habían formado parte de espectáculos que constaban de danzas, recitales de poesía o música, donde la txalaparta era uno más de estos elementos, como Ikimilikiliklik o Baga, biga, higa sentikaria. En los Encuentros de Pamplona, por petición expresa de De Pablo, la txalaparta se presenta de forma autónoma (Joxean Artze, comunicación personal, 18 de agosto de 2015).

Tras los Encuentros, en 1975 los hermanos Artze grabaron en Milán, en los estudios Ricordi, el disco Txalaparta '75 iraila, editado por el sello italiano Cramps Records, especializado en música contemporánea. Los responsables del sello vieron clara la conexión entre la txalaparta de los hermanos Artze y la música repetitiva hecha por aquel entonces por músicos de vanguardia norteamericanos (Zabala 2003, 38). En 1976, De Pablo realizó la composición Zurezko olerkia (Poema de madera) que incluyó la txalaparta de los hermanos Artze. En esta composición la txalaparta se incluye de forma libre, improvisando sin partitura, mientras que los demás instrumentos, todos ellos de madera, sí cuentan con partitura (Zabala 2003, 45). 


\section{LA FASCINACIÓN DE REICH Y CAGE}

En una entrevista realizada después de los Encuentros de Pamplona, Cage manifestaba su interés por la txalaparta (Jover y Amestoy 1972), y otros testimonios también apuntan a su fascinación por la txalaparta (Alejos 2010), pero también al interés que tuvieron los hermanos Artze por la música de Cage (Ruiz y Huici 1974). Joxean Artze apunta que Juan Hidalgo, también del grupo ZAJ y que tenía relación con Cage, les había contado que éste había manifestado que "lo mejor que ha habido en los Encuentros de Pamplona ha sido la txalaparta y John Cage" (comunicación personal, 18 de Agosto de 2015).

Por su parte, Reich se interesó vivamente por la txalaparta, sus patrones rítmicos y por el timbre de sus maderas. El artista y músico Jose Mari Zabala afirma que Reich estaba claramente muy interesado en la txalaparta y que fue muy insistente, rayando la obsesión, para conseguir escuchar más txalaparta. Según él, días después de los Encuentros acudieron a cenar al restaurante de los padres de Zumeta en un barrio de Usurbil, probablemente el lunes 3 o el martes 4 de julio. A esta cena asistieron Rafael Ruiz-Balerdi, Jesus y Joxean Artze, Jose Mari Zabala, Laura Dean, Steve Reich y el grupo de bailarinas de la compañía de Dean (comunicación personal, 27 de agosto de 2015). Además, según los testimonios de Reich y Dean, en algún otro momento de su estancia ambos, que eran pareja en ese momento, estuvieron en Donostia y también visitaron a los maestros de txalaparta de los Artze (Hurtado 2015, 108-13).

A partir del cuaderno de notas que Reich escribió durante ese verano, donde recogió sus impresiones tras el concierto de los Artze, varios autores especulan sobre la influencia que la txalaparta habría tenido en la composición Clapping, que Reich estaba desarrollando en ese momento ${ }^{2}$, y en la posterior Music for pieces of wood de 1973 (Potter 2011, 37). Esta última consta de cinco pares de claves de madera que son percutidos, cada uno por un intérprete distinto, superponiendo diversos ritmos que cambian durante la interpretación. En la entrevista realizada por Euba, que hemos mencionado antes, Reich reconoce que el contacto con la txalaparta, junto con la música de percusión de Ghana que había estudiado anteriormente, influyeron en la citada composición. 


\section{CARACTERÍSTICAS VANGUARDISTAS DE LA TXALAPARTA}

El interés de los músicos de vanguardia por la txalaparta es a priori paradójico, ¿cómo es posible que la txalaparta, un instrumento de origen rural y calificado de "particular" e incluso "primitivo", y que ha llamado poco la atención de estudiosos de la cultura y música vasca, fascinara a músicos como Cage o Reich? Sin embargo, la relación entre la txalaparta y la música de vanguardia existe tanto a nivel histórico como a nivel formal y conceptual.

Una de las composiciones donde algunas de estas similitudes formales son apreciables es In C de Terry Riley (1964), cuya premier es contemporánea del primer momento de recuperación de la txalaparta. Riley nos propone aquí una situación donde, a partir de un material musical pre-definido, y mediante la improvisación colectiva, se construye una estructura donde las relaciones entre los intérpretes son cruciales para la evolución de la macroestructura, pero también para la microestructura de la pieza. Más que una composición, en el sentido clásico del término, Riley plantea una situación que al ponerse en marcha, y a través de una improvisación colectiva, da lugar a infinitas variaciones de la pieza.

Las similitudes formales comprenden diferentes aspectos, como la existencia de un material musical predefinido que limita y da carácter al proceso musical. En el caso de $\ln C$, sería su partitura que consta de 53 motivos melódicos, mientras que en la txalaparta serían las combinaciones de golpes en las que cada intérprete puede subdividir su parte del compás $(0,1$ y 2 golpes en txalaparta antigua, y actualmente $0,1,2,3,4$ o más), así como la forma de repartir el tiempo del compás en alternancia entre ambos intérpretes. Otro aspecto es la existencia de instrucciones que delimitan qué se puede hacer y cómo, con el material disponible. En In $C$ serían las direcciones de interpretación adjuntas a la partitura y en la txalaparta serían las reglas, no escritas, que establecen los roles que ambos intérpretes toman, su forma de interactuar, y la estructura general que puede tomar la actuación. Finalmente encontramos en ambas la improvisación colectiva, a través de la escucha, como elemento vertebrador de la estructura temporal y auténtico motor de la obra.

En cuanto a otros aspectos formales y conceptuales comunes entre la música experimental de los años 60 y la txalaparta, podemos apreciar características centrales del lenguaje de la txalaparta y de la música experimental, como son la exploración del timbre, el uso de la repetición y el pulso, la falta de interés 
por la melodía -que no aparece en la txalaparta hasta muy recientemente- o el énfasis en la duración temporal (relación sonido-silencio) como elemento constructivo de la música.

La economía de medios es tal en la txalaparta, especialmente en la antigua, que las menores variaciones tímbricas son significativas y su exploración resulta muy importante durante la interpretación, al igual que en muchas obras de música contemporánea, especialmente en obras de la denominada escuela minimal y de compositores Fluxus, como La Monte Young.

La repetición es muy usada por las artes modernas, y en el caso de la música, tiene dos aspectos, por un lado, el uso de máquinas permite realizar repeticiones exactas -esto está en el germen de la música minimal tal y como documenta Glover $(2013,3)$ - y por otro, la imposibilidad del intérprete humano de repetir con exactitud un mismo gesto. Algunas composiciones de Young son paradigmáticas de esta imposibilidad, como $X$ for Henry Flint o Composition 1960 \#7, ambas de 1960. En la txalaparta el ritmo más habitual es binario con subdivisiones de dos golpes (conocido como txakun) y es rara la actuación de txalaparta en la que no hay varios compases, si no la mayoría, dominados por la repetición de este patrón rítmico. En el caso de txalaparta más tradicional, esto es aún más extremo. El intérprete que llevaba el rol de txakun lo mantiene durante toda la actuación, con lo que las irregularidades, como en las citadas composiciones de Young, resaltan enormemente.

Otro recurso formal presente en la txalaparta, y que vuelve a ser usado por algunos de los autores de música experimental a partir de los años 60 , es el pulso, que había quedado relegado del vocabulario de la música contemporánea en favor de la complejidad rítmica, según Curran (Pardo 2009, 88) y Wolff (Pardo 2009, 100). A partir de In C el pulso vuelve a ser usado por los compositores "minimalistas" como Reich, Riley o Philip Glass, entre otros. La txalaparta, por su parte, consta de un pulso normalmente inestable, especialmente en txalaparta antigua. A pesar de esto, el pulso aporta una direccionalidad a las interpretaciones dotándolas de un carácter hipnótico y trascendente, no lejano al de la música experimental basada en un pulso estable y repeticiones, de la que Curran dice "cuyo único fin es el deseo de elevación y de trascendencia" (Pardo 2009, 88).

Finalmente, tenemos el interés, que manifiesta Cage, por la construcción de la música a partir de la relación sonido-silencio. Esto responde a un intento de escapar de las convenciones de la música occidental principalmente basada 
en las relaciones de frecuencia (armonías y melodías), al contrario que otras culturas donde la duración (relación sonido-silencio) es tan importante o más. La txalaparta, menos en los pocos casos donde la melodía tiene un papel importante, es un vehículo perfecto para el desarrollo de estos conceptos. La música de los hermanos Artze es un ejemplo paradigmático de uso de la tensión entre sonido y silencio en la construcción musical.

\section{CONCLUSIÓN}

La musicalidad de la txalaparta ha sido objeto de debate y muchos la consideran más cercana al ruido que a la música. Sin embargo, muchos artistas y músicos locales e internacionales se han interesado enormemente por la txalaparta. Otras tradiciones musicales populares también han generado el interés de los músicos de vanguardia, pero en la txalaparta hay dos elementos singulares: la construcción del compás en alternancia y la influencia del pensamiento de vanguardia en el proceso de recuperación y reinvención que se produce en los años 60 y 70 . Además, en la txalaparta podemos encontrar muchas características formales exploradas por la música de vanguardia, como son la indefinición rítmica y tonal, la improvisación colectiva, la exploración del timbre, la economía del lenguaje, la repetición y el pulso, o la existencia implícita de reglas que rigen el toque. Esta cercanía con el lenguaje de la vanguardia es lo que probablemente ha llevado a que muchos músicos alineados con la corriente más ortodoxa de la música la hayan considerado como algo "raro" y "no musical".

\section{Referencias}

Alejos Garizabal, Nerea. 2010. "La huella imborrable de los encuentros". Noticias de Navarra, 23 de abril, http://lainformacionsa.net/20100423/culturaysociedad/lahuellaimborrableencuentros.html

Bailey, Derek. (1980) 2010. La improvisación, su naturaleza y práctica en la música. Gijón: Trea

Beltran Argiñena, Juan Mari. 1985. "Euskal Herriko soinu tresnak". Documental [productor, guionista, director]. Vídeo de Youtube, 4:14. Acceso 25 febrero 2014, http://youtu.be/nZAkMUQrPKM

_ 1988a. "Txalaparta". En Aurrera Begira, Heda Saila 5, 181-206. Bilbao: Udako Euskal Unibertsitatea

- 1988b. "Txalaparta". Cuadernos de Etnologia y Etnografía de Navarra 52, 419-39 
- 2001a. "Soinutresna batzuk Euskal Herri musikan". En XV Congreso de Estudios Vascos. Donostia: Eusko Ikaskuntza

- 2001b. "Lan erritmoetatik musikara". Jentilbaratz 7, 119-55. http://hedatuz.euskomedia. org/6957/1/07119155.pdf

- 2004. Txalaparta eta beste aldaera zaharrak: Lan erritmoetatik musikara [La txalaparta, antecedentes y variantes: De los ritmos de trabajo a la música]. Oiartzun: Herri Musikaren Txokoa

- 2007. "Hernaniko txalaparta eskolaren 12 ikasurte". Jentilbaratz 9: 151-72

- 2009a. Txalaparta. Donostia: Nerea

- 2009b. Txalaparta. DVD. Donostia: Nerea

- 2012. "Txalaparta”. En Auñamendi Entziklopedia. Acceso 8 enero 2014. http://www.euskomedia.org/aunamendi/132599

Díaz Cuyás, José et al. 2010. Encuentros de Pamplona 1972 : fin de fiesta del arte experimental. Madrid: Museo Nacional Centro de Arte Reina Sofía

Encuentros Pamplona. 1972. Encuentros 1972 Pamplona, 26 VI-3 VII. Luis de Pablo y J.L. Alexanco, dirs. Madrid: Alea

Escribano del Moral, María. 2012. "Rhythms of Struggle: Recovery, Revival and ReCreation of Txalaparta in the Basque Country." Tesis Univ. of Limerick (Irlanda)

Euba Ugarte, Argibel. 2004. "Txalaparta: Transcription and Analysis." Trabajo fin de máster. University of London

- 2006. "Txalaparta, una aproximación general". Manuscríto inédito

Gambra Uriz, Anai. 2008. "Relación entre la frecuencia fundamental propia de una tabla de Iroko (Chlorophora excelsa) y sus dimensiones: Aplicación a la txalaparta." Trabajo final de grado Univ. de Lleida. https://repositori.udl.cat/handle/10459.1/45893?show=full

Glover, Robert. 2013. "Minimalism, Technology and Electronic Music". En The Ashgate research companion to minimalist and postminimalist music, edited by Keith Potter, Kyle Gann and Pwyll ap Sion, 161-81. Farnham, UK: Ashgate

Goiri Iturrizar, Josu. 1996. Txalaparta. Los dos sonidos del corazón. Arrigorriaga: Josu Goiri Iturrizar

Hobsbawm, Eric \& Terence Ranger, eds. 1983. La invención de la tradición. Trad. castellana de Omar Rodríguez Estellar. Barcelona : Crítica

Hontañón y Huidobro Cagigal y Pardo de Santayana, Leopoldo. 1972. "Primeros encuentros de Pamplona". $A B C, 6$ de julio

Hurtado Mendieta, Enrique. 2015. "La txalaparta digital: Un análisis de la txalaparta a través del desarrollo de software". Tesis Univ. del País Vasco

Jover Portilla, José Luis \& Dámaso Santos Amestoy. 1972. “John Cage, primera figura de la música de vanguardia". Pueblo, 5 de agosto

Kortazar Uriarte, Jon. 1998. "Artzeren poesiaren pentsakizunaz". Lapurdum 8, 285-328

Leaf, Helen. 2007. "An Introduction to the Basque Txalaparta." The Galpin Society Journal 60:215-19

Neira Díaz, Fernando. 2006. "Tomás San Miguel y la txalaparta feliz." El País, 26 de marzo, http://elpais.com/diario/2006/03/25/babelia/1143245179 850215.html

Pardo Salgado, Carmen \& Makis Solomos. 2009. ¿Los límites de la composición?: ciclo La casa Encendida, del 10 al 16 de marzo de 2008. Madrid: La Casa Encendida 
Potter, Keith. 2011a. "Drummed Out? What Steve Reich did after Drumming". Mitteilungen der Paul Sacher Stiftung 24:35-41

- 2011b. "Steve Reich Clapping music (1972)". Reseña del programa de mano 'London Symphony Orchestra Living music, Wednesday 12 \& Saturday 15 October, LSO St Luke's and Barbican Hall, Programme notes, 6.

Ruiz, Javier \& Fernando Huici. 1974. La comedia del arte (en torno a los encuentros de Pamplona). Madrid: Editora Nacional

Sánchez González, Francisco Javier. 1998. “Txalaparta: Breve estudio acústicomusical”. Txistulari, 162: 19-23

- 2006. "Vibración de la Txalaparta". En Acceso 8 enero 2014. www.aldebaransoft.es/Txalaparta/txalaparta2.htm

Sánchez González, Francisco Javier \& Juan María Beltrán Arguiñena. 1998. "Una teoría numérica del ritmo aplicada a la txalaparta". Txistulari 173: 27-43

Sánchez González, Francisco Javier \& Manuel Siguero Guerra 2000. "Txalaparta. Vibración y timbre”. XXXI Congreso Nacional de Acústica-TecniAcústica. www.ia.csic.es/sea/4375kk. $\underline{\text { html }}$

Suso Biain, Maigua Lorea. 2004. "La txalaparta y su cambio de contexto en la sociedad vasca". Nassarre: Revista Aragonesa de Musicología 21(1): 253-64

Zabala Artetxe, Juan Luis. 2003. Jesus Mari Artze, ttakunaren esku isila. Usurbil: Zumarte

Notas

${ }^{1}$ Más que música genera sonido sin sentido lógico, cercano a la vanguardia (traducción del autor).

2 Más información en la reseña de Keith Potter (2011) en el programa de mano sobre "Clapping music" de la London Symphony Orchestra (Neil Percy, Stive Reich, handclappers. Barbican Hall, Saturday 15 October).

(Artículo recibido 26-11-15; aceptado 09-12-15) 